Artículo

\title{
Apuntes sobre el fascismo tardío
}

\section{Notes on Late Fascism}

\author{
Alberto Toscano* \\ *Goldsmiths College
}

\section{Resumen:}

Este artículo propone pensar el presente con base en elementos de algunas de las teorías del fascismo elaboradas durante el siglo XX, desde Bloch y Bataille a Adorno, Pasolini, Sartre y Banaji. Se trata en la actualidad de un fascismo sin movimiento que lo sostenga ni revolución a la cual enfrentarse. El fascismo contemporáneo o "tardío" trata más bien de proyectos que descansan en fantasías raciales de renacimiento nacional acompañadas de una frenética circulación de discursos pseudoclasistas. El propósito es entonces ofrecer algunos aspectos elementales de las manifestaciones actuales del fascismo como política conservadora de una reproducción antagonista, y así repensar lo que significa hoy una política colectiva.

Palabras clave: Fascismo; No-simultaneidad; Clase obrera blanca.

\begin{abstract}
:
This article proposes to think the present by refunctioning elements of some theories of fascism advanced in the twentieth century, from Bloch and Bataille to Adorno, Pasolini, Sartre and Banaji. Today, we are confronted with fascisms devoid either of mass movements that support them or of a revolutionary antagonist whom they confront. Contemporary or "late" fascism are rather best captured as projects that draw on racial fantasies of national rebirth, accompanied by a frenetic circulation of pseudo-classist discourses. The objective of these notes is to introduce an analysis of some of the elementary aspects of the current manifestations of fascism as a conservative politics of antagonistic reproduction, so as to rethink what a collective politics means today.
\end{abstract}

Keywords: Fascism; Non-Synchronicity; White Working Class. 
Recibido: 16 de mayo de 2019

Aceptado: 14 de julio de 2019

Quienes se encuentran viviendo en tiempos de crisis y desorientación suelen buscar guía en el pensamiento analógico. El parecido de una coyuntura con otra promete la preparación necesaria para no encontrarse otra vez en falta, para evitar los errores culpables de precursores desarmados de previsión. Consideremos como ejemplo sorprendente de este recurso a la analogía -entre los incontables que han circulado antes y después de la grotesca coronación de Trump-el diagnóstico de Franco Berardi 'Bifo' en un post en el sitio web DiEM25 de Yannis Varoufakis et al. titulado "Obrerismo nacional y guerra racial", publicado el 10 de noviembre de 2016 y reiterado en su intervención en una conferencia en Viena en diciembre de ese mismo año bajo el título “¿Un nuevo fascismo?", junto a intervenciones de Chantal Mouffe y del disidente y filósofo comunista húngaro Gáspár Tamás ${ }^{1}$ :

Tal y como lo hicieron en 1933, los trabajadores se han vengado en contra de aquellos que los han embaucado: los políticos de la izquierda reformista "democrática". (...) Esta "izquierda" debiera ser arrojada al basurero: ha abierto el camino al fascismo al escoger servir al capitalismo financiero e implementar "reformas" neoliberales. (...) Debido a su cinismo y cobardía, han enviado a la gente a manos de las corporaciones y los gobiernos de nuestras vidas. Al hacer esto, han abierto la puerta al fascismo que hoy se esparce y a la nueva guerra civil que parece ahora imparable. (...) La clase trabajadora blanca, humillada durante los últimos treinta años, embaucada por interminables promesas reformistas, empobrecida por la agresión financiera, ha elegido ahora al Ku Klux Klan para la Casa Blanca. En tanto la izquierda ha quitado de las manos de los

\footnotetext{
${ }^{1}$ Para un resumen del panel, ver Franco Berardi, Wilhelm Heitmeyer, Chantal Mouffe y G. M. Tamás, “A New Fascism?", 29 de diciembre de 2016, consultado en junio de 2020, disponible en https://www.youtube.com/watch?v=QHj7fE2I10.
} 
trabajadores las herramientas democráticas de autodefensa, ahora se viene la versión racista de la guerra de clases².

La analogía del fascismo -inextricablemente enmarañada con su símil infraestructural, la analogía de la crisis económica- es mi punto de partida aquí. No deseo explorar directamente el poder cognitivo o estratégico de dicha analogía (sea en tiempo presente o en iteraciones anteriores) para calibrar cómo puede permitirnos ver y actuar, sino más bien usarla como ocasión para reflexionar acerca de lo que algunas teorías filosóficamente orientadas del fascismo propuestas en el siglo XX pueden indicar acerca del nexo contemporáneo entre política e historia, generalmente por vía de determinadas desanalogías. Así, mi propósito no es el de responder a la pregunta "¿es esto fascismo?", sino antes bien el de discernir algunos efectos que tiene el proyectar teorías del fascismo en el presente, y quizás aprender algo a partir de esta refracción.

Muy provisionalmente, pienso que dichas teorías nos permiten confrontar la peculiaridad de un fascismo sin movimiento, sin utopía; un fascismo desprovisto de lo que Bloch llamara nocontemporaneidad y Bataille denominara heterogeneidad; un fascismo que no está reaccionando a la amenaza de una política revolucionaria, sino que retiene la fantasía racial del renacimiento nacional y la frenética circulación de un discurso pseudoclasista. Quiero también sugerir que esto último se entiende mejor no por complicidad con la figura sociológicamente espectral de la clase trabajadora blanca "olvidada", sino haciendo frente a lo que significa hoy una política colectiva, en el entendido de que aceptar este simulacro racializado de un proletariado no es ningún trampolín hacia una política de clase, sino que es más bien su obstáculo, su malévola forma sucedánea. El propósito es entonces esbozar, para el debate y la disputa colectiva, algo así como los aspectos elementales de una pseudoinsurgencia - con la salvedad de que, en muchos sentidos, una pseudoinsurgencia fue lo que encarnó el fascismo asesino del período de entreguerras en Europa.

Para todas sus disputas sobre la adecuada aproximación teórica al surgimiento del fascismo después del cataclismo de la Primera Guerra Mundial, la mayoría de los teóricos marxistas de la época se aproximaron al fenómeno desde la interfaz entre lo político y lo económico, buscando adjudicar la funcionalidad de la supresión fascista de la democracia parlamentaria liberal a la

\footnotetext{
${ }^{2}$ Franco Berardi, "National Workerism and Racial Warfare", 10 de noviembre de 2016, consultado en junio de 2020, disponible en https://diem25.org/national-workerism-and-racial-warfare/.
} 
reproducción intensificada de las condiciones para la acumulación capitalista ${ }^{3}$. Esto llevó a identificar el fascismo con la solución de la clase dominante a la crisis orgánica de un régimen de acumulación enfrentado a la amenaza de la lucha de clases organizada, en medio de las vacilaciones de un orden imperialista; pero es también reconocer a veces las contradicciones entre la autonomía o primacía de lo político, brutalmente declarada por movimientos fascistas, y la posibilidad de la reproducción del modo capitalista de producción. De ahí los debates de las décadas de los treinta y cuarenta, especialmente estimulados por los trabajos de teóricos de la Escuela de Frankfurt como Friedrich Pollock y Franz Neumann sobre la viabilidad del capitalismo de estado, debates que continúan siendo iluminados por trabajos históricos contemporáneos como el impresionante Wages of Destruction de Adam Tooze ${ }^{4}$. Sin descontar las alianzas tácticas que diversos sectores de la clase capitalista de Estados Unidos (desde el cemento a la seguridad privada, el petróleo y los automóviles) puedan tener con la administración Trump, poco hay en el presente, especialmente en lo que concierne a algún reto a la hegemonía capitalista, que autorice en mi opinión a este respecto la analogía con el fascismo, sobre todo a la luz de las significativas protestas de corporaciones, la comparativa atracción del capital por el estilo de neoliberalismo socialmente consciente de Hillary Clinton que promete mantener la paz social y la rentabilidad, el enigma del proteccionismo, y así sucesivamente.

Antes bien, el carácter intensamente superestructural de los rasgos fascistas de nuestro presente parece autorizar el llevar la mirada hacia otro lado. Muchos ya han comentado acerca de la posibilidad de recuperar percepciones de las incursiones psicosociales que la Escuela de Frankfurt (otra vez) hizo del fenómeno del fascismo, desde los escritos de Fromm, Marcuse y Horkheimer sobre el sadomasoquismo pequeñoburgués en su Estudio sobre la autoridad y la familia hasta la serie de posguerra "Estudios sobre el Prejuicio", con sus estudios empíricos sinópticos sobre la personalidad autoritaria. Retornaré a ellos más adelante para reflexionar sobre algunas intuiciones de Adorno acerca de la psicología de masas y el narcisismo, pero antes quiero intentar pensar con una de las entradas más heterodoxas del debate filosófico de entreguerras sobre el fascismo, Herencia de esta época de Ernst Bloch. Este trabajo proteico, fascinante e inquietante

\footnotetext{
${ }^{3}$ Para una introducción lúcida y matizada al debate marxista desde el punto de vista de la década de los setenta, ver Anson Rabinbach, "Toward a Marxist Theory of Fascism and National Socialism: A Report on Developments in West Germany", New German Critique 3 (1974): 127-153.

${ }^{4}$ Adam Tooze, The Wages of Destruction: The Making and Breaking of the Nazi Economy (Nueva York: Penguin, 2006).
} 
-que una vez y con intención peyorativa fuera comparado por Walter Benjamin al intento por esparcir alfombras persas maravillosamente brocadas sobre un campo en ruinas ${ }^{5}$ - contiene una reflexión central y con justicia famosa sobre "La no-contemporaneidad y las obligaciones de su dialéctica". Al igual que Bataille, aunque en un registro muy diferente, Bloch se aproxima al fascismo no desde el nivel del instrumento político ni de la patología psicológica sino del de la promesa utópica pervertida. A pesar de los elementos cruciales que esto oculta a su mirada ${ }^{6}$, este ángulo de visión permitió a Bloch identificar sus características energizantes populares, las que a su juicio sus contrapartes marxistas y comunistas habían efectivamente fallado en movilizar. Subyace al argumento de Bloch la idea de que el socius se encuentra atravesado por temporalidades plurales; la estructura de clases de la sociedad moderna está ensombrecida por múltiples tiempos culturales e históricos que no existen sincrónicamente. El ocultismo racista y conspirativo de los nazis aprovecha esta experiencia vivida del desarrollo desigual:

Se cree en el incumplimiento de la "esclavitud a las tasas de interés" (Zinsknechtschaft) como si fuera la economía de 1500; las superestructuras que parecían hace tiempo derrocadas se enderezan a sí mismas y se detienen en el mundo actual como escenas completas de la ciudad medieval. Aquí está la Taverna de la Sangre Nórdica, allí el castillo del duque de Hitler, allá la Iglesia del Reich Alemán, una iglesia terrenal en la cual incluso la gente de ciudad puede sentir que son ellos mismos fruto de la tierra alemana y honrar la tierra como algo sagrado, como la confessio de los héroes alemanes y la historia alemana (...) Los campesinos a veces creen aún en brujas y exorcistas, pero ni de cerca con tanta frecuencia y

\footnotetext{
5 “La objeción más seria que tengo con este libro (si acaso no también con su autor) es que en modo alguno corresponde a las condiciones en las cuales aparece, sino que inapropiadamente asume un lugar, como un gran señor que, llegando a la escena de un área devastada por un terremoto, no encuentra nada más urgente que hacer que extender alfombras persas (las que, a propósito, ya están comidas por hongos) y desplegar los recipientes dorados y plateados de algún modo deslucidos y los ya desvanecidos brocados y prendas damasco que han traído sus sirvientes", en Walter Benjamin, Carta a Alfred Cohn del 6 de febrero de 1935, citado en Anson Rabinbach, "Unclaimed Heritage: Ernst Bloch's Heritage of Our Times and the Theory of Fascism”, New German Critique 11 (1977): 5.

${ }^{6}$ Como indica Rabinbach, subrayando la significación de las reflexiones de Benjamin sobre capitalismo, tecnología y espectáculo modernos: "Bloch enfatiza la continuidad entre fascismo y la tradición encarnada en sus ideas, pero descuida aquellos elementos de discontinuidad con los elementos del pasado que dan al fascismo su poder único como forma de organización social, de modo que sus vínculos reales con el capitalismo moderno permanecen ocultos", ibid., 14.
} 
tan fuertemente como las amplias clases urbanas creen en judíos fantasmales y en el nuevo Baldur. Los campesinos a veces leen todavía los así llamados Libros Sexto y Séptimo de Moisés, un tratado sensacional sobre enfermedades de animales y fuerzas y secretos de la naturaleza; pero la mitad de la clase media cree en los Sabios de Zion, en trampas judías y la omnipresencia de símbolos masones y en los electrizantes poderes de la sangre alemana y la tierra alemana ${ }^{7}$.

Si la lucha de clases entre la burguesía capitalista y el proletariado es una lucha sobre la modernización, lo sincrónico o lo contemporáneo, en el período de entreguerra muchos (de hecho la mayoría) de los alemanes vivieron tanto en términos sociales como psicológicos por medio de formas sociales y fantasías psíquicas incrustadas en diferentes ritmos e historias. Consciente de que sería erróneo ver cualquiera de estas formas como meramente primitivas, en un país donde las relaciones sociales de producción nunca estuvieron realmente fuera del capitalismo, Bloch quiere detectar las formas en que, cuando se trata de sus miedos (de degradación o anomia) y deseos (de orden o bienestar), estos grupos se encuentran de algún modo fuera de sintonía con el presente racionalizador del capitalismo, ese espacio iluminado que fuera ocupado por los movimientos convencionales de socialistas y trabajadores. Para Bloch, durante la década de los treinta Alemania era un país habitado no solo por ciudadanos, trabajadores y explotadores desencantados. La crisis ha traído a la "gente no sincrónica" al frente: remanentes a la baja de un pasado cuyas esperanzas permanecen encendidas y que los vuelve fácilmente reclutables para las filas de la reacción.

En un sentido a la vez social y psíquico, la coyuntura política se ve desgarrada entre el Ahora antagonista e incumplido del conflicto capitalista y los pasados incompletos que rebosan en sus intersticios. El efecto emocional colectivo es una "rabia reprimida" que los nazis y sus impulsores capitalistas son capaces de desenterrar y de exacerbar, mientras que permanece fuera de alcance para un comunismo cuyo racionalismo iluminista se arriesga a devenir prácticamente irracional. De modo que la "clase alta capitalista monopólica (...) utiliza sueños góticos contra realidades proletarias". La cuestión de cómo relacionarse intelectual y políticamente con lo no-

\footnotetext{
${ }^{7}$ Ernst Bloch, "Nonsynchronism and the Obligation to Its Dialectics", M. Ritter trans., New German Critique 11 (1977): 26. Este texto es un extracto de The Heritage of Our Times. [Hay edición en castellano: Herencia de esta época, Miguel Salmerón trad. (Barcelona: Editorial Tecnos, 2019). NdT.]
} 
sincrónico se vuelve esencial, pues se ha vuelto inútil el consolarse uno mismo con el cuento evolucionista según el cual lo arcaico será gradualmente erosionado por el progreso social y económico. "La teoría del nacionalsocialismo no es seria, pero sí lo es su energía, su impacto fanático-político, el que no viene sólo del desespero y la ignorancia sino más bien del poder único y conmovedor de la creencia", escribe Bloch ${ }^{8}$. Aunque la estrategia política del proletariado debe ser por fuerza sincrónica si es que va a confrontar al Ahora capitalista, se requiere también recuperar y dar forma al tipo de no-sincronicidad desde donde provienen demandas inmemoriales e invariantes por justicia. Bloch articula esta tarea incumplida y "no reconocida" en términos de la relación entre dos formas de contradicción: por un lado, la negatividad sincrónica y determinada del proletariado organizado; por el otro, esas positividades "subversivamente utópicas" que "no han recibido cumplimiento en ninguna época". En este sentido, Bloch estaba tratando de suplementar un pensamiento de la contradicción "sincrónica" entre capital y trabajo y las “contradicciones no-sincrónicas" que implicaba a clases fuera de sintonía con los ritmos y sitios de la acumulación de capital (campesinos, pequeña burguesía, aristocracia, lumpen proletariado, etcétera).

Como señala Rabinbach, citando de Heritage,

La contradicción entre estas dimensiones temporales demanda lo que Bloch llama "la obligación de su dialéctica", un reconocimiento de complejidad que no sólo se enfoca en lo sincrónico sino que en lo no-sincrónico, en las contradicciones multitemporales y multiestrato dentro de un mismo presente. Para Bloch, es precisamente la sedimentación de experiencias sociales lo que crea el intenso deseo por una resurrección del pasado entre estos grupos, los más susceptibles a la propaganda fascista. Para el marxismo, el problema es que la ideología fascista no es simplemente un instrumento de engaño sino "un fragmento de un antagonismo antiguo y romántico al capitalismo, derivado de las deprivaciones de la vida contemporánea, con una nostalgia por un vago 'otro", 9 .

\footnotetext{
${ }^{8}$ Bloch, The Heritage of Our Times, citado en Rabinbach, "Unclaimed Heritage", 13-4.

${ }^{9}$ Ibid., 7.
} 
Para Bloch, el punto es identificar al fascismo como una "estafa de plenitud" -en su fantástica frase- mientras se toma en serio la urgencia por plenitud y el modo en que éste reactiva pasados incumplidos y futuros irrealizados. Ahora, ¿podemos volver hoy a esta compleja dialéctica de "salvamiento" invocada por Bloch (para quien no es sólo en fases de élan emancipatorio, sino que también en períodos derivados "de declive en los que la multiplicidad de contenidos es liberada en su desintegración" desde los que uno puede revitalizar una herencia revolucionaria)? Aquellas teorías críticas que, desde el período inmediatamente de posguerra en adelante, han enfatizado la evanescencia o borramiento de la diferencia cultural o temporal desde la experiencia vivida de las economías capitalistas avanzadas, han puesto serias dudas sobre esta posibilidad.

Una sociedad "posmoderna", "unidimensional” o "administrada" se define quizás sobre todo por esta mengua de historicidad, lo que por supuesto puede ser acompañado por la proliferación de su simulacro instrumentalizado. Un interesante testamento de esto podría encontrarse en los controversiales artículos de periódico de mediados de los setenta en los que Pier Paolo Pasolini, poco antes de su asesinato, buscó articular la diferencia entre un fascismo viejo y uno nuevo. Este último, que para Pasolini era consustancial a un neocapitalismo represivamente hedonista con sus mecanismos abiertos y encubiertos de conformidad total, estaba marcado por el borramiento del pasado en la forma de lo que llamó (en supuesta -aunque quizás mistificadorareferencia a El manifiesto comunista) un "genocidio antropológico", a saber, la muerte de las experiencias vinculadas a tiempos y formas de vida campesinas y "populares", un "genocidio" que él registraría incluso en la transformación de los propios cuerpos, gestos y posturas ${ }^{10}$. Para Pasolini, el viejo fascismo (y aquí la referencia es estrictamente a su variante italiana) fue incapaz de deshacer o transformar realmente -podríamos decir, de "sincronizar"- esas formas de vida profundamente incrustadas. Esto resultaba evidente en la forma en que ellas reemergieron, aparentemente ilesas, después de la muerte de Mussolini. Esto contrasta con el poder total del capitalismo contemporáneo, a saber, el de la intensiva reformulación y homogeneización de deseos y formas de vida (especialmente bajo la apariencia de diversidad, elección y libertad), el que significaba la destrucción de todo signo de desigualdad histórica, con todos sus potenciales

\footnotetext{
${ }^{10}$ Pier Paolo Pasolini, "Il vuoto di potere in Italia", Il Corriere della Sera, 10 de febrero de 1975. El artículo sería republicado luego en Scriti Corsari, una colección de intervenciones periodísticas de Pasolini publicada poco después de su muerte. [Hay edición en castellano: Escritos corsarios, Mina Pedrós trad. (Barcelona: Editorial Planeta, 1983). NdT.]
} 
utópicos. En la visión profundamente pesimista de Pasolini, y contra Bloch, ya no quedaban pasados que rescatar.

Ahora, ¿cómo podríamos revisitar estas preguntas de fascismo y no-contemporaneidad en nuestro tiempo? Quizás se puede comenzar con una enorme ironía dialéctica: las tendencias fascistas que encuentran expresión en la elección de Trump, pero también en proyectos nacionalistas y revanchistas contemporáneos a lo largo de "Occidente", son aparentemente conducidas por una nostalgia por la sincronicidad. No hay aquí pasados arcaicos o tradiciones inventadas, sino la nostalgia por la imagen de un momento (ese de la afluencia de la posguerra, de los trente glorieuses), de una imagen racializada y genderizada del obrero industrial patriótico socialmente reconocido (el obrerismo nacionalista de Bifo podría también ser llamado fordismo nacional o racial, el que curiosamente reprime las condiciones regulatorias estatales de esta fantasía). Para emplear los términos de Bloch, esta es una nostalgia por lo sincrónico, por lo contemporáneo. El emblema autorizado de una modernidad industrial de posguerra posutópica y despolitizada, el trabajador-ciudadano industrial, reaparece ahora (sin duda más como fantasía que como hecho, o bien en la penosa mise-en-scène de "trabajadores mineros" rodeando al presidente de los Estados Unidos mientras éste abole las regulaciones ambientales) en el disfraz del "hombre olvidable", las "personas no-sincrónicas" del presente político. Si esto es una utopía, se trata de una utopía sin trascendencia, sin elemento "fanático-religioso" alguno, sin un excedente de energías populares inconsciente o tácito.

Tal y como la dialéctica no-sincrónica ha sido transmutada hoy en la paradójica nosincronicidad de lo sincrónico (o la nostalgia por una modernidad fordista, la utopía de una era posutópica), así la paralela identificación de Bataille acerca del atractivo del fascismo en su dinámica manipulación de la heterogeneidad (esa que es inconmensurable con la metódica autorreproducción del orden capitalista, sea desde abajo como exceso de masas o desde arriba como soberanía irresponsable) requiere una corrección en el presente. Las tendencias fascistas actuales contienen poca, si es que alguna, relación con dicho exceso libidinal, excepto en la degradada forma vestigial de lo que podríamos llamar el "líder obsceno", en analogía con la noción psicoanalítica del "padre obsceno". Y esto se encuentra también vinculado a la ausencia de uno de los rasgos históricos claves del fascismo, a saber, la amenaza revolucionaria al orden capitalista, demandando que esa homogeneidad se vacune a sí misma con el exceso (o con su simulacro) para 
así sobrevivir. Como Bataille anotó en su ensayo acerca de "La estructura psicológica del fascismo":

Como regla, la homogeneidad social es una forma precaria, a merced de la violencia e incluso del disenso interno. Se forma espontáneamente en el juego de la organización productiva, pero debe ser constantemente protegida de los varios elementos ingobernables que no se benefician de la producción, o no lo suficiente para encajar en ella, o que simplemente no pueden tolerar los controles que la homogeneidad impone al descontento. En dichas condiciones, la protección de la homogeneidad descansa en su recurso a los elementos imperativos [el carácter fundamentalmente excesivo de la soberanía monárquica] que son capaces de borrar a las varias fuerzas ingobernables o ponerlas bajo control del orden ${ }^{11}$. La ausencia señera de algo así como un movimiento de masas en las manifestaciones contemporáneas del fascismo (lo que se ve más destacado aun cuando la actual derecha del nacionalismo racial anuncia su carácter de movimiento cada vez que tiene ocasión) puede también ser visto como un signo de esta falta de heterogeneidad y no-sincronicidad, la ausencia palpable de lo utópico y lo antisistémico en los gérmenes del fascismo actual.

Para desarrollar más esta intuición, vale la pena explorar en cierto detalle la relevancia para el debate contemporáneo de los debates acerca de la psicología de masas del fascismo. No únicamente Bataille con su intervención, sino muchos miembros de la Escuela de Fráncfort, vieron el ensayo de Freud "Psicología de las masas y análisis del "yo"” de 1922 como un parteaguas en el estudio de los nexos entre política colectiva y deseo individual, en especial en lo que respecta a su análisis del liderazgo. La influencia del texto de Freud fue vasta y variada (para una interesante reflexión contemporánea, ver el trabajo de Stefan Jonsson ${ }^{12}$ ), pero quiero considerarla aquí por medio de un texto de Adorno de posguerra, "La teoría freudiana y las pautas de la propaganda fascista" (1951), el que puede ser tomado también como un tipo de correctivo a las lecturas salvajes

\footnotetext{
${ }^{11}$ Georges Bataille, “The Psychological Structure of Fascism”, Carl L. Lovitt trans., New German Critique 16 (1977): 66. [Hay edición en castellano: La conjuración sagrada. Ensayos 1929-1939, Silvio Mattoni sel., trad. y pról. (Buenos Aires: Adriana Hidalgo editora, 2003). NdT.]

12 Stefan Jonsson, Crowds and Democracy: The Idea and Image of the Masses from Revolution to Fascism (Nueva York: Columbia University Press, 2013).
} 
del fascismo propuestas por Bloch y Bataille. El interés del texto de Adorno se ve sólo incrementado por el hecho de que se relaciona con una investigación, a saber, su propia participación en el proyecto de investigación colectiva en La personalidad autoritaria y el libro de Löwenthal y Guterman sobre los agitadores fascistas estadounidenses, Profetas del engaño, el que con justicia ha sido aludido como iluminador del fenómeno Trump ${ }^{13}$.

En Profetas del engaño, Löwenthal y Guterman trazan el siguiente retrato teórico compuesto del agitador fascista estadounidense:

El agitador no confronta a su audiencia desde afuera; antes bien, parece como alguien que surge de entre medio para expresar sus pensamientos más profundos. Por decir así, trabaja desde dentro de la audiencia, agitando lo que yace ahí dormido. Los temas son presentados con un aire frívolo. Los enunciados del agitador son por lo general ambiguos y poco serios. Es difícil concretizarlo en algo, y da la impresión de que es deliberadamente teatral. Parece estar tratando de dejar para sí un margen de incertidumbre, una posibilidad de retirada en caso de que falle alguna de sus improvisaciones. No se compromete porque está dispuesto, al menos temporalmente, a hacer malabarismos con sus nociones y testear sus poderes. Moviéndose en la zona crepuscular entre lo respetable y lo prohibido, está listo para usar cualquier recurso, desde bromas a hipocresías a extravagancias salvajes. (...) Se refiere de forma vaga a las inadecuaciones e inequidades de la estructura social existente, pero no se hace responsable en último caso por los males sociales, como lo hace el revolucionario. (...) El reformador y el revolucionario generalizan las actitudes rudimentarias de la audiencia en una conciencia elevada de sus predicamentos. Las demandas originales pasan a ser sublimadas y socializadas. La dirección y los efectos psicológicos de la actividad del agitador son

\footnotetext{
${ }^{13}$ Un examen de la lista de "temas" de la agitación fascista estadounidense da una idea de dicha iluminación: "Los engaños eternos", "Conspiración", "El fruto prohibido" (sobre el goce de los ricos); "Desafección"; "La mascarada de muerte", "Los rojos" "Los plutócratas", "El gobierno corrupto", "El extranjero" (con su subsección "El refugiado").
} 
radicalmente diferentes. Las energías gastadas por el reformador y el revolucionario para elevar las ideas y emociones de la audiencia a un plano de conciencia más alto son usadas por el agitador para exagerar e intensificar los elementos irracionales en la demanda original (...) Al contrario de todos los otros programas de cambio social, el contenido explícito de su material de agitación es en último análisis incidental -es como el contenido manifiesto de los sueños. La función primaria de las palabras del agitador es la de liberar reacciones de gratificación o frustración cuyo efecto total es supeditar a la audiencia a su liderazgo personal. (...) Se niega a distinguir entre lo insignificante y lo significativo; no hay queja ni resentimiento que sea demasiado pequeño para la atención del agitador. Lo que generaliza no es una percepción intelectual; lo que produce no es la conciencia intelectual del predicamento, sino un agravamiento de la propia emoción. En vez de construir un correlato objetivo de la insatisfacción de su audiencia, el agitador tiende a presentarla a través de una imagen fantástica y extraordinaria, la que es un estiramiento de las propias proyecciones de la audiencia. Las soluciones del agitador pueden parecer incongruentes y moralmente chocantes, pero son siempre fáciles, simples y finales, como ensueños. En vez del esfuerzo específico demandados por el reformador y el revolucionario, el agitador parece requerir solo la voluntad de renunciar a las inhibiciones. $\mathrm{Y}$ en vez de ayudar a sus seguidores a sublimar la emoción original, el agitador les da permiso para complacerse en fantasías anticipatorias en que ellos descargan violentamente esas emociones contra supuestos enemigos. (...) Por medio de la explotación del miedo del caos inminente, el agitador tiene éxito en aparecer como el radical que no hará tratos con meras reformas fragmentarias, mientras que simultáneamente dirige a sus 
adherentes bien lejos de cualquier sugerencia de una reorganización social básica ${ }^{14}$.

¿Cómo es que Adorno busca teorizar esta intensificación “microfascista” y antagonística, pero en ultimo termino conservadora, de un "malestar" que unifica el sentido de impotencia agencial a la desorientación del individuo humillado ante la totalidad enigmática, transmutada aquí en conspiración? Lo hace tomando un desvío por vía de "Psicología de las masas y análisis del "yo"” de Freud. Lo que encuentra, especialmente en lo que se relaciona con las formas del fascismo en un contexto de posguerra, es decir posfascista, es quizás más instructivo para el presente que las reflexiones filosóficas de entreguerras sobre el fascismo como un fenómeno revolucionario.

Adorno quiere moverse desde los recursos de agitación identificados por Löwenthal y Guterman, los cuales tienen como sus "ingredientes indispensables (...) reiteraciones constantes y escasez de ideas”"15, hacia la estructura psicológica que les subyace. Como ha señalado Peter E. Gordon en su riquísima revisión de las contribuciones de Adorno para pensar el fenómeno Trump ${ }^{16}$, las reflexiones de Adorno se ven orientadas por su comprensión del fascismo como fenómeno vinculado a la crisis de la individualidad burguesa como experiencia psíquica y como forma social. O, en la ocurrencia dialéctica del propio Adorno, "podemos al menos aventurar la hipótesis de que la psicología del antisemita contemporáneo presupone en cierto sentido el fin de la psicología propiamente tal" ${ }^{17}$. Adorno observa respecto de Freud que "desarrolló, dentro de los confines monadológicos del individuo, las trazas de su crisis profunda y de su voluntad para ceder agencia colectiva a un afuera poderoso de modo incuestionado"18. Adorno se concentra en el problema del lazo libidinal que el fascismo requiere, de modo vertical hacia el líder (especialmente bajo el disfraz de un tipo de juego narcisista en el que el seguidor se encuentra a sí mismo reflejado en el propio ensimismamiento del líder) y horizontalmente, hacia sus pares o camaradas racializados, e identifica este rasgo como un problema técnico o psicotécnico para el propio fascismo. Comentando la obsesión de los nazis con el adjetivo "fanático" (objeto de una brillante

\footnotetext{
${ }^{14}$ Leo Löwenthal y Norbert Gutermann, Prophets of Deceit. A Study of the Technique of American Agitator (Nueva York: Harper, 1949), 5-9, 34.

15 Theodor W. Adorno, "Freudian Theory and the Pattern of Fascist Propaganda", en The Frankfurt School Reader, Andrew Arato y Eike Gebhardt eds. (Nueva York: Continuum, 1982), 119. [Hay edición en castellano: Ensayos sobre la propaganda fascista. Psicoanálisis del antisemitismo (Barcelona: Editorial Voces y Cultura, 2003). NdT.]

${ }^{16}$ Peter E. Gordon, "The Authoritarian Personality Revisited: Reading Adorno in the Age of Trump", Boundary2.Org, 15 de junio de 2016, consultado en junio de 2020, disponible en https://www.boundary2.org/2016/06/peter-gordonthe-authoritarian-personality-revisited-reading-adorno-in-the-age-of-trump/.

${ }^{17}$ Theodor W. Adorno, "Comentarios sobre la Personalidad Autoritaria" (1958), citado en Gordon, ibídem.

${ }^{18}$ Adorno, "Freudian Theory", 120.
} 
entrada por parte de Victor Klemperer en La lengua del Tercer Reich ${ }^{19}$ ), y con Hitler evitando el rol del padre amado, Adorno comenta: "Es uno de los principios básicos del liderazgo fascista el mantener la energía libidinal primaria en un nivel inconsciente, cosa de desviar sus manifestaciones en una forma que calce con fines políticos" ${ }^{20}$. Esta energía libidinal es por necesidad personalizada como un "vínculo erótico" (en términos de Freud) y opera por medo del mecanismo psicoanalítico de la identificación (otra vez, tanto horizontal como verticalmente).

A nivel psicoanalítico, el fascismo se alimenta de la contradicción entre el conatus autopreservante del ego y sus deseos constantemente frustrados. Este es un conflicto que "resulta en fuertes impulsos narcisistas que pueden ser absorbidos y satisfechos únicamente por medio de una idealización, como la de la transferencia parcial de libido narcisista al objeto [es decir, al líder] (...) al hacer del líder su ideal, se ama a sí mismo, como si fuera, pero se libera de las presiones de la frustración y el descontento que estropean su retrato acerca de su propio yo empírico" 21 . Más aun, "en función de hacer posible la identificación narcisista, el líder mismo tiene que aparecer como absolutamente narcisista (...) el líder puede ser amado únicamente si él mismo no ama" ${ }^{22}$. Incluso en su lenguaje, el líder depende de su parecido psicológico con sus seguidores, un parecido que se revela en el modo de desinhibición, y más específicamente en "discursos desinhibidos, pero enormemente asociativos" "23 "La ganancia narcisista provista por la propaganda fascista es obvia. Sugiere de forma continua y a ratos retorcida que, simplemente por pertenecer al grupo, el seguidor es mejor, más alto y puro que quienes están excluidos. Al mismo tiempo, cualquier tipo de crítica o autoconciencia es resentida como una pérdida narcisista y provoca furia" 24 .

Pero el hecho que indica que, más usualmente que no, el líder fascista aparece como un “actor de reparto" [ham actor] y "psicópata asocial" es una pista de que, antes que sublimidad soberana, lo que debe transmitir es algo del sentido de inferioridad del seguidor: tiene que ser un "pequeño gran hombre". El comentario de Adorno es instructivo aquí:

La ambivalencia psicológica ayuda a obrar un milagro social. La imagen del líder gratifica el deseo dual del seguidor de entregarse a una autoridad y de ser él mismo autoridad. Esto se ajusta a un mundo

\footnotetext{
${ }^{19}$ Victor Klemperer, LTI: La lengua del Tercer Reich. Apuntes de un filólogo (Barcelona: Editoral Minúscula, 2001).

${ }^{20}$ Ibid., 123.

${ }^{21}$ Ibid., 126.

${ }^{22}$ Ibid., 126-27.

${ }^{23}$ Ibid., 132.

${ }^{24}$ Ibid., 130.
} 
en el que el control irracional es ejercido como si hubiera perdido su convicción interna por medio del iluminismo universal. La gente que obedece a los dictadores también percibe que éstos son superfluos. Ellos reconcilian esta contradicción por medio de asumir que ellos mismos son el despiadado opresor ${ }^{25}$.

Esta pérdida de "convicción interna" en la autoridad es a mi juicio la verdadera intuición de las reflexiones de Adorno sobre la propaganda fascista, y donde se mueve más allá de un Freud todavía maniatado en su dependencia de las energías psicológicas reaccionarias de La psicología de las masas de Le Bon. Esto se relaciona una vez más al "fin de la psicología", es decir, a la crisis de una cierta forma de individualidad, lo que Adorno considera como el contexto epocal de la emergencia del fascismo. El líder-agitador puede explotar su propia psicología para afectar la de sus seguidores ("para hacer uso racional de su irracionalidad", en la formulación de Adorno) porque es el mismo también un producto de la cultura de masas que drena autonomía y espontaneidad de sus sentidos. En contraste con el énfasis de Bataille y Bloch en la perversión de la revolución provocada por el fascismo, su mecanismo psicosocial depende según Adorno de su rechazo de todo lo que requiera trascender el status quo, sea social o psíquicamente.

El fascismo es retratado aquí como una forma de política conservadora de la reproducción antagónica, la reproducción de algunos en contra de otros, y en el límite una reproducción fundada sobre su no-reproducción o eliminación. Antes que una preocupación emancipatoria por la igualdad, el fascismo promueve un "igualitarismo represivo" basado en una identidad de sujeción y una hermandad de odio: "El trasfondo del igualitarismo malicioso, de la hermandad de una humillación integral, es un componente de la propaganda fascista y del fascismo como tal" (es su "truco de la unidad" ${ }^{26}$. En una autocrítica acerca del individualismo psicológico que rigiera $L a$ personalidad autoritaria, Adorno argumenta ahora que el fascismo no tiene causas psicológicas sino que define un "área psicológica", un área compartida con fenómenos no fascistas y que puede ser explotada por puro interés particular, en lo que es una "apropiación de la psicología de masas", "la expropiación del inconsciente por el control social en vez del hacer a los sujetos conscientes de su inconsciente". Este es "el punto de inflexión donde la psicología abdica". ¿Por qué? Porque a lo que nos estamos enfrentando no es una dialéctica de expresión o represión entre individuo y

${ }^{25}$ Ibid., $127-28$.

${ }^{26}$ Ibid., 131. 
grupo, masa o clase, sino con los "átomos pospsicológicos desindividualizados que forman las colectividades fascistas" $27 . Y$ mientras estas colectividades pueden parecer "fanáticas", su convicción es hueca, aunque para nada menos peligrosa por eso. En esto reside el "fingimiento" del fanatismo fascista, el que para Adorno estaba ya funcionando con el nazismo, para toda la transmisión de su propio fanatismo:

La categoría de "fingimiento" [phoniness] aplica a los lideres tanto como al acto de identificación de parte de las masas en su supuesto frenesí e histeria. Esta gente cree ciegamente en el líder tan poco como creen, en el fondo de sus corazones, que los judíos son el diablo. No se identifican realmente ellos mismos con el líder sino que actúan esta identificación, escenifican su propio entusiasmo, y participan así de la performance del líder. Es por medio de esta performance que encuentran equilibrio entre sus urgencias instintivas continuamente movilizadas y la etapa histórica de ilustración que han alcanzado, y que no puede ser revocada de modo arbitrario. Es probablemente la sospecha de esta naturaleza ficticia de su propia "psicología de grupo" lo que vuelve a las hordas fascistas tan implacables e inabordables. Si se detuvieran por un segundo, toda la performance se caería a pedazos y entrarían en pánico $^{28}$.

Este "fanatismo fingido" potencialmente mortífero difiere de aquel del "verdadero creyente" (y podríamos detenernos a pensar sobre el problema que los fascistas revolucionarios, desde los nacional-bolcheviques a los futuristas, han puesto por lo general a sus propios regímenes) de un modo que apunta a la crucial dependencia del fenómeno fascista sobre variedades del "truco de la unidad", sobre varias formas de unidad ficticia. Aquí las reflexiones de Jairus Banaji ${ }^{29}$ sobre el fascismo en India incluye una percepción clave, a saber, los usos contemporáneos en los que pueden ser utilizadas las reflexiones de Sartre sobre "serialidad manipulada" para analizar la violencia fascista. El "grupo soberano" fascista actúa por medio de la transformación de la

\footnotetext{
${ }^{27}$ Ibid., 136.

${ }^{28}$ Ibid., 136-37.

${ }^{29}$ Jairus Banaji, "The Political Culture of Fascism", HistoricalMaterialism.Org, 19 de febrero de 2017, consultado en junio de 2020, disponible en http://www.historicalmaterialism.org/blog/political-culture-fascism.
} 
existencia serial de los individuos en la vida social (los "átomos pospsicológicos desindividualizados" de Adorno) en una falsa totalidad, sea ésta la nación, el partido o la raza (y generalmente los tres). Como señala Banaji, "[1] a serialidad manipulada se encuentra en el corazón de la política fascista", por lo que no es cualquier masa la que es conjurada por el fascismo (de hecho, el miedo a las masas está entre sus factores psicopolíticos originales, como ha mostrado brillantemente Klaus Theweleit en los análisis de los escritos de los Freikorps en su trabajo Male Fantasies $^{30}$ ), sino una masa controlada externamente y que nunca "fusiona" en un grupo, una masa que debe producir macroefectos en la oferta del grupo "dirigido por otros" [hetero-directed], todo mientras permanece dispersa. En una versión diferente pero no desconectada del problema de la democracia liberal despolitizadora, Este es el problema del fascismo: ¿cómo hacer actuar a las mayorías sin que ganen agencia colectiva, y sobre todo sin deshacer la agencia directiva de la minoría (del grupo)? Perspicazmente, Banaji alista el aparato categorial del Sartre de la Crítica de la razón dialéctica para pensar por medio del "pogromo" fascista:

El pogromo es así un caso especial de esta "dirección por otros" en la que el grupo "intenta actuar en la serie de tal modo de extraer una acción total de ella en la propia alteridad". El grupo directriz es cuidadoso de "no ocasionar lo que puede ser llamado acción organizada dentro de conjuntos inertes". "El problema real a este nivel es extraer acciones orgánicas de las masas" sin interrumpir su estatuto de masa molecular dispersa, de serialidad. De este modo, Sartre define el pogromo como "la actividad pasiva de una serialidad dirigida", un análisis donde el término "pasivo" solo subraya el punto de que la responsabilidad de mando es el factor crucial en la violencia comunal, en tanto los individuos envueltos en actos dispersos de violencia son los instrumentos inertes de un grupo soberano o directriz. Entonces, para Sartre la complicidad pasiva que sostiene la base de masas del fascismo es una complicidad serial, una "responsabilidad serial" como él la llama, y en principio no hace diferencia si los individuos de la serie han participado en atrocidades como parte de una ola orquestada de pogromos, o ellos

\footnotetext{
${ }^{30}$ Klaus Theweleit, Male Fantasies, dos volúmenes (Minneapolis, University of Minnesota Press, 1987/1989).
} 
simplemente aprobaron esa violencia "en una dimensión serial", como él lo dice ${ }^{31}$.

El hecho que Sartre haya visto la serialidad como un factor crucial a la propia constitución del estado moderno y sus prácticas de soberanía sugiere también que la frontera entre una dirección por otros de tipo fascista y otra no fascista puede ser más porosa de lo que el sentido común liberal puede sugerir. Aunque podríamos decir también que el fascismo destaca en la manipulación sistemática de las serialidades generadas por la vida social capitalista, moldeándolas en pseudounidades o falsas totalidades.

Si aceptamos el nexo entre el fascismo y la serialidad, entre una política que es controlada externamente y en la cual las "relaciones horizontales" son de pseudocolectividad y pseudounidad, y en las que yo interiorizo la dirección del Otro como mi mismidad con ciertos otros (viene a la mente aquí la analogía de Sartre en Crítica de la razón dialéctica, vol. 1, entre el racismo cotidiano y el fenómeno de los Top Ten), entonces debiéramos ser cautelosos en analizarlo con categorías que asumen la existencia de totalidades reales. Esto es lo que creo incumbe a una izquierda crítica, o de hecho antifascista, para dejar de complacerse en la retórica ambivalente del votante de la clase trabajadora blanca como el sujeto que se supone votó por la opción fascista-populista. Esto no solo se relaciona con la cuestionabilidad sociológica del argumento electoral, o con el enorme peso que da a las clases medias y altas, o incluso con las vergonzantes formas de condescendencia autosatisfecha que permite a ciertos comentaristas o lectores académicos o periodísticos, o la forma en que permite a la izquierda complacerse en fantasías para las cuales "si tan sólo pudiéramos movilizarlos...". Más fundamentalmente, se trata de que, políticamente hablando, la clase obrera como colectivo y no como serialidad manipulada no existe (todavía). Conferirle el espectro de la emancipación es entonces profundamente erróneo, más allá de los estudios estadísticos sobre aquellos fenómenos inherentemente seriales, las elecciones.

Imputar la subjetividad de una agencia histórica a una totalidad política falsa no es solo repetir involuntariamente el "truco de la unidad" de la propaganda fascista, sino que es también suponer que las formas y energías políticas emancipatorias yacen latentes en la vida social. Como provocación, podemos adaptar la sentencia de Adorno citada anteriormente y leer: "[Debemos] al

\footnotetext{
${ }^{31}$ Jairus Banaji, "Trajectories of Fascism: Extreme-Right Movements in India and Elsewhere", Eprints.SOAS.Ac.Uk, 18 de marzo de 2013, consultado en junio de 2020, disponible en https://eprints.soas.ac.uk/16825/1/Jamia\%20lecture\%20(fascism).pdf.
} 
menos aventurar la hipótesis de que la identidad de clase del votante actual de Trump presupone en cierto sentido el fin de la clase propiamente tal". Un signo de esto es, por supuesto, lo pegajoso del calificativo racial clase obrera blanca. Alain Badiou señaló alguna vez sobre la fraseología del terrorismo islámico que "cuando un predicado es atribuido a una sustancia formal (...) no tiene otra consistencia que la de dar un contenido ostensible a esa forma. En 'terrorismo islámico' el predicado ‘islámico' no tiene otra función que la de suministrar un contenido aparente a la palabra 'terrorismo', la que en sí misma se encuentra desprovista de todo contenido (político, en este ejemplo)"32. La blanquitud es aquí -y no sólo al nivel del discurso, sino que yo diría que al de la experiencia política- el suplemento de un vacío político o noción espectral de la clase obrera. Es lo que permite a una agencia pseudocolectiva verse imbuida de contenido psicosocial (tóxico). Esto es del todo patente si notamos el modo en que incesantemente, en el discurso público y en la pseudoreflexión estadística, la blanquitud es fundamental para pertenecer a esta "clase obrera", mientras que toda relación con los medios de producción es cuando más opcional, por así decir. La experiencia racializada de la clase no es un factor autónomo en la emergencia de tendencias fascistas dentro del estado capitalista, sino que es la proyección de ese estado, una serialidad manipulada. Es así una experiencia diferente en tipo a la de la conciencia de clase política, y probablemente sin solución de continuidad hacia ella. En un análisis brillante y aún vital, Ètienne Balibar definió el racismo como un suplemento del nacionalismo:

El racismo no es una "expresión" del nacionalismo sino su suplemento o, más precisamente, un suplemento interno del nacionalismo, siempre excediéndose en relación con él, pero siempre indispensable para su constitución, y no obstante aún insuficiente para acabar su proyecto, tal y como el nacionalismo es a la vez indispensable y siempre insuficiente para alcanzar la formación de la nación o el proyecto de "nacionalización" de una sociedad. (...) Como suplemento de la particularidad, el racismo primero se presenta a sí mismo como un supernacionalismo. El nacionalismo meramente político es percibido como una posición débil y conciliatoria en un universo de competencia o guerra sin cuartel (el lenguaje de la "guerra económica" internacional se

\footnotetext{
${ }^{32}$ Alain Badiou, Infinite Thought: Truth and the Return of Philosophy (Londres: Continuum, 2003), 153.
} 
encuentra más extendido hoy que de lo que nunca lo ha estado). El racismo se ve a sí mismo como un nacionalismo "integral", que tiene sentido (y posibilidades de éxito) únicamente si se encuentra basado en la integridad de la nación, tanto hacia afuera como hacia adentro. Lo que el racismo teórico llama "raza" o "cultura" (o ambas juntas) es entonces un origen continuado de la nación, un concentrado de las cualidades que pertenecen "como propiedad" a los nacionales; es en la "raza de sus hijos" que la nación pudo contemplar su propia identidad en estado puro. En consecuencia, se debe agrupar alrededor de la raza, debe identificarse con la raza, "patrimonio" que hay que preservar de cualquier tipo de degradación, tanto "espiritualmente" como "física" o "carnalmente" (y lo mismo ocurre para la cultura como sustituto o expresión interna de la raza $)^{33}$.

En intentos contemporáneos de promover y analizar fantasías fascistas y políticas de "renacimiento nacional", la clase arriesga transformarse a su vez en un suplemento (de ambos, racismo y nacionalismo), atrapada en las cámaras de eco de la propaganda serializante. No hay forma de partir desde la falsa totalidad de una clase racializada y dirigida por otros y llegar a un renacimiento de la política de clase; no hay forma de trasformar las estadísticas electorales e investigaciones mal diseñadas en un "sujeto populista" y en los "hombres y mujeres olvidados", ni en un lugar desde el que repensar una impugnación al capital, ni para analizar y desafiar los fundamentos mismos del discurso fascista. Cualquiera de esas opciones necesitará tomar distancia del sujeto pseudoclasista que ha alzado su cabeza en la escena política. Este falso renacimiento del discurso de clase es en sí mismo parte de la estafa, y otro recordatorio de que no es el menor de los peligros del fascismo la fascinación y confusión que siembra en las filas de sus oponentes debido a su oportunismo sin límites. Antes de pensar que una clase obrera que ya existe necesita ser recuperada de los engaños del fascismo, mejor nos irá si nos alejamos de esa falta totalidad y repensamos, como uno de los anticuerpos del fascismo, la formación o composición de una clase capaz de negarse a ser convertida en la portadora de un predicado racial o nacional.

\footnotetext{
${ }^{33}$ Étienne Balibar, "Racism and Nationalism", en É. Balibar e I. Wallerstein, Race, Nation, Class: Ambiguous Identities (Londres: Verso, 1988), 54 y 59. [Hay edición en castellano: Raza, nación y clase (Madrid: Iepala textos, 1991). NdT.]
} 


\section{Tesis preliminares sobre el fascismo tardío}

Tesis 1 (con Bloch): el fascismo tardío se beneficia de la no-contemporaneidad o no-sincronicidad, excepto por la no-sincronicidad de los sincrónico, la nostalgia de una modernidad industrial posutópica.

T1 Corolario 1 (con Bataille): el fascismo de hoy es muy débil sobre el excedente heterogéneo necesario para reproducir la homogeneidad capitalista, tanto al nivel "soberano" (o imperativo) como al de la "base" (sea exceso lumpen o motivaciones inconscientes).

T1 Corolario 2 (con Pasolini): el nuevo fascismo es un fascismo de la homogeneización disfrazada como jouissance de la diferencia.

T2 (con Freud y Adorno): la estructura psíquica del fascismo opera a través de una forma de narcisismo de masas.

T3 (con Adorno): el fascismo tardío opera a través de una performance de fanatismo desprovista de convicción interna, aunque su "fingimiento" no hace que la violencia disminuya.

T4 (con Adorno): el fascismo (tardío) es una política conservadora de reproducción antagonista.

T5 (con Banaji y Sartre): el fascismo (tardío) no es la política de una clase, de un grupo o de una masa, sino de una serie manipulada.

T6: en la producción y recepción del fascismo tardío, el significante racializado de la clase funciona como espectro, como pantalla y como suplemento; un racismo que es a la vez un suplemento necesario del nacionalismo (una definición mínima de fascismo como la afirmación del suplemento, y su transformación más o menos abierta en ingrediente clave del estado-nación).

T7: el fascismo tardío es impulsado por un deseo por el estado y un odio al gobierno. 
T8: el fascismo tardío reacciona contra lo que es ya una reacción liberal; no es primeramente contrarrevolucionario.

T9: el fascismo tardío no se consolida por el esfuerzo de la clase gobernante en hacer uso de la autonomía de lo político para lidiar con un límite externo al capital, sino por una de las ramificaciones de una crisis de legitimidad del capital que es endógena y prolongada, y en la que lo político es autónomo más al nivel de la fantasía que de su función.

T10: el fascismo tardío es un síntoma de la tóxica obsolescencia de la figura moderna de lo político, a saber, un "estado nacional y social" en el que la ciudadanía es organizada a través de ejes de identidad etnoracial y de género, y articulada al trabajo.

\section{Agradecimientos}

Este artículo fue elaborado en primera instancia como presentación en un Seminario en la Simon Fraser University (British Columbia, Canadá) en febrero de 2017. El autor agradece a Clint Burnham por la hospitalidad y camaradería, y a los participantes por su involucramiento crítico. Traducción desde el inglés por Felipe Lagos Rojas. 


\section{Referencias bibliográficas}

Adorno, Theodor W. "Freudian Theory and the Pattern of Fascist Propaganda". En The Frankfurt School Reader, editado por Andrew Arato y Eike Gebhardt. Nueva York: Continuum, 1982.

Badiou, Alain. Infinite Thought: Truth and the Return of Philosophy. Londres: Continuum, 2003.

Balibar, Étienne. "Racism and Nationalism", en Race, Nation, Class: Ambiguous Identities, Étienne Balibar e Immanuel Wallerstein. Londres: Verso, 1988.

Banaji, Jairus. "The Political Culture of Fascism". HistoricalMaterialism.Org, 19 de febrero de 2017. Consultado en junio de 2020, disponible en http://www.historicalmaterialism.org/blog/political-culture-fascism.

"Trajectories of Fascism: Extreme-Right Movements in India and Elsewhere". Eprints.SOAS.Ac.Uk, 18 de marzo de 2013. Consultado en junio de 2020, disponible en https://eprints.soas.ac.uk/16825/1/Jamia\%201ecture\%20(fascism).pdf.

Bataille, Georges. "The Psychological Structure of Fascism”, traducción de Carl L. Lovitt. New German Critique 16 (1977).

Berardi, Franco. "National Workerism and Racial Warfare". 10 de noviembre de 2016. Consultado en junio de 2020, disponible en https://diem25.org/national-workerism-and-racial-warfare/.

Berardi, Franco, Wilhelm Heitmeyer, Chantal Mouffe y G. M. Tamás. “A New Fascism?”. Conferencia en Viena. 29 de diciembre de 2016, consultado en junio de 2020, disponible en https://www.youtube.com/watch?v=-QHj7fE2I1o.

Bloch, Ernst. "Nonsynchronism and the Obligation to Its Dialectics", traducción de M. Ritter. New German Critique 11 (1977).

Gordon, Peter E. "The Authoritarian Personality Revisited: Reading Adorno in the Age of Trump". Boundary2.Org, 15 de junio de 2016. Consultado en junio de 2020, disponible en https://www.boundary2.org/2016/06/peter-gordon-the-authoritarian-personality-revisitedreading-adorno-in-the-age-of-trump/.

Löwenthal, Leo y Norbert Gutermann. Prophets of Deceit. A Study of the Technique of American Agitator. Nueva York: Harper, 1949.

Pasolini, Pier Paolo. "Il vuoto di potere in Italia". Il Corriere della Sera, 10 de febrero de 1975.

Rabinbach, Anson. "Toward a Marxist Theory of Fascism and National Socialism: A Report on Developments in West Germany". New German Critique 3 (1974). 
. "Unclaimed Heritage: Ernst Bloch's Heritage of Our Times and the Theory of Fascism". New German Critique 11 (1977).

Theweleit, Klaus. Male Fantasies, dos volúmenes. Minneapolis, University of Minnesota Press, 1987/1989.

\section{Sobre el autor}

Alberto Toscano. Profesor en teoría crítica y codirector del Center for Philosophy and Critical Thought en Goldsmiths College, University of London (Londres, Reino Unido). Doctor en Filosofía por la Universidad de Warwick, Reino Unido, y estudió también en New School for Social Research (Nueva York) y University College Dublin (Dublín). Ha publicado Cartographies of the Absolute (Londres: Zero Books, 2015) en coautoría con Jeff Kinkle, Fanaticism: On the Uses of an Idea (Londres: Verso, 2010), y The Theatre of Production: Philosophy and Individuation Between Kant and Deleuze (Londres: Palgrave Macmillan, 2006). Se encuentra preparando el libro Late Fascism (Londres: Verso, 2021). Miembro del equipo editorial de la revista Historical Materialism: Research in Critical Marxist Theory desde 2004. Ha traducido varios libros de Alain Badiou al inglés, entre ellos Logics of Worlds (Londres: Continuum, 2004) y The Century (Londres: Polity, 2007), así como trabajos de Antonio Negri, Furio Jesi y Franco Fortini. Correo electrónico: a.toscano@gold.ac.uk. 